\title{
Web Service Oriented Architecture Solution for Accounting Information System for SMEs Legal Firm
}

\author{
Mumtazimah Mohamad, Zuhairah Ariff Abd Ghadas, Wan Nur Syahida Wan Ismail, Fatimah \\ Ghazali
}

\begin{abstract}
The need for efficient account management is critical because it gives an additional advantage to strategic information management. Accounting systems for legal firms involving distinct business processes and practices with client records and a reasonably detailed account of its own. Although currently there is a lot of accounting software locally and internationally, however, it is not appropriate to the needs of world-class firms, small and medium enterprises (SMEs), especially in terms of size, scope and cost. Majority of them manage the account by themselves such as manually record keeping or non-integrate system. Therefore, it is not surprising when the legal practitioner SMEs have difficulties in managing their account. Computerized Accounting Information Systems (CAIS@Law) is proposed as a web service to help SMEs firms in managing financial transactions, performance monitoring firm, statements of cash flows and inflows out customer's account and the auditing process. Business process requirements have been identified, namely using web services oriented architecture through the virtual server. It requires a basic operating system, easy and reduced cost and customizable and easy to operate. This system can provide sufficient material for submission to the Bar Council as proof of the account as well as the use of a variety of clients and SME sector scale. The developed prototype successfully employed by local SMEs and shows competitive features with dynamics customization ability based on the capacity of the firm.
\end{abstract}

Index Terms - Accounting system, law firms, service-oriented architecture, SMEs, web services.

\section{INTRODUCTION}

Legal firms usually manage a lot of paperwork to run the business. Obviously, legal firms do not only deal with the management of clients and businesses, but also towards keeping tracks with expenses, revenues, payrolls and other great challenge to cope, especially with the increasing numbers of clients and cases of urgent demands. Thus, the balance between their laws practices, as well as their company managements need to be balanced to maintain their survival and relevancies in business. There is an absolute need for a systematic, flexible and remote account

Revised Manuscript Received on July 10, 2019.

Mumtazimah Mohamad, Faculty of Informatics and Computing, University Sultan Zainal Abidin, Besut Campus, Besut, Terengganu, Malaysia.

Zuhairah Ariff Abd Ghaddas, Faculty of Law and International Relation, University Sultan Zainal Abidin, Kuala Nerus, Terengganu, Malaysia.

Wan Nur Syahida Wan Ismail, School of Maritime Business and Management, University Malaysia Terengganu, Kuala Nerus, Terengganu, Malaysia.

Fatimah Ghazali, Faculty of Informatics and Computing, University Sultan Zainal Abidin, Besut Campus, Besut, Terengganu, Malaysia. related financial management matters. These tasks can be a

management in assisting legal firms especially for smalland-medium (SMEs) sized firms. The account management should adopt and adapts the requirements and processes of legal business much better compared to general accounting information systems. Legal activities, services and processes shall be streamlined into an improved and centralized database in order to enhance the efficiencies, productivities and managements. All essential information and processes of firm's management should be in an integrated system and act as main references and records of daily financial transactions. Basic accounting systems mostly focus on financial accounting that records account and generates reports for stakeholders, administrations and managements which supports cost analysis for internal decision making and strategic planning [1]. Meanwhile, the accounting information systems for SMEs should be more focus on modules of client's profiles, client's accounts and office's accounts. The proposed system considers documents such as vouchers, receipts, invoices, bank statements and client's information.

The Software as a Service is a cloud computing service that provides cost effective model to carry out business applications especially in SMEs. This model has been proved to reduce cost, simultaneously provides a better option and access to global innovations [2]. Furthermore, this kind of model has great advantages in dealing with the resource constraints, complexities of business process, installing and maintaining the required infrastructures, upgrading level of service for/from vendors, reducing cost of upfront and upgrades, flexible and manageable IT resources and improving the infrastructure scalabilities [1]. For the SMEs account management systems, the proposed web services should be able to coordinate business processes and identify the relationships from both function and non-functional perspectives. This web services shall have features such as self-contained, modular, and dynamically applicable especially in improving procedures and business processes, distributed or web based and uses open and standards web protocols to support heterogeneities across the platform and language boundaries.

This paper will discuss the related works on the requirements of SMEs's accounting systems, proposed application system that adapts web services methodology and discussions on the importance and effectiveness of the system.

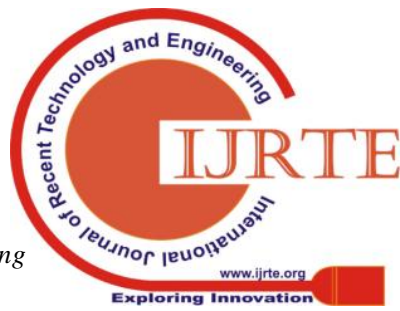




\section{WEB SERVICE ORIENTED ARCHITECTURE SOLUTION FOR ACCOUNTING INFORMATION SYSTEM FOR SMEs LEGAL FIRM}

\section{RELATED WORKS}

Most of SMEs companies face a lot of constraints typically due to limited resources and insignificant effects to their market competitiveness [3], [4]. SMEs should be creative in utilizing their resources to adapt to the market segment [5]. A cost effective decision-making plays important role to the success of the SMEs firms [6] as the manager should be very skillful, effective in management as well as good in information technology (IT) in order to make effective decisions [7].

IT based application is obviously an important business tools to SMEs in order to minimize cost of production and labour [8]. Furthermore, IT applications can facilitate niche marketing innovation as well as increase the productivities and its effectiveness [9]. Not only that, efficiencies of internal business operations can be enhanced [10], and the firm can be innovative to grab competitive advantages [8], [11]. Moreover, IT application can improve collaborations and network strength of SMEs such as stakeholders, institutions, other parties and other business contacts.

In the market, there are variations of off-the-shelf application with general use in the market. Mostly, there are similar applications for all area of practices. These softwares are good, however they are just purely focus on the financial areas and do not satisfy the requirement and transaction focuses on legal firms. In contradict with other companies; law firms manage client's accounts and office's accounts separately to ensure the accountability managements of the client's moneys. Therefore, the account's managements of legal firms cannot be tackled by the general accounting system. Currently, various of software for account's management systems in legal firms have been developed, but majority of them are complex and only applicable to big sized firms. Since most of the legal firms in Malaysia can be categorized as SMEs, these systems are irrelevant to be used due to the integration of extensive and advanced accounting software [12]. Moreover, SMEs actually have their own scopes of business and segments. Thus, there are no requirements of a complex business process other than fulfilling the company's objectives. In this case, it would be ineffective, if the costs are being spent to unneeded features for their firm. These factors urged to the need for a Turnkey System for law firms. Turnkey System is a system which written by vendors who specialize in a particular industry [13]. For that reason, this research proposed an accounting turnkey based system which is able to fulfill the specific requirements of attorneys and SMEs law firms. Table 1 shows the list of vendors which provide cloud computing software. In this case, it might be incurred an additional cost for the cloud solutions in maintaining cloud system.

Table 1: Comparison of software for legal small firm in the market

\begin{tabular}{|c|l|c|}
\hline Software/Origin & \multicolumn{1}{|c|}{ Features } & Price \\
\hline & $\bullet$ accounting & \\
Legalmaster, & $\begin{array}{l}\text { open item accounts } \\
\text { USA }\end{array}$ & USD695 \\
& $\begin{array}{l}\text { receivable } \\
\text { accounting } \\
\end{array}$ & $\begin{array}{c}\text { per } \\
\text { license/user }\end{array}$ \\
\hline
\end{tabular}

- task billing and electronic billing

- report management

- revenue distribution

- originating attorney

- conflict of interest

- calendar and case management

- connections to other law office application software products

- accounts management

$£ 1,129.13$

- case manager

- record and billing

Manager, UK

- perfect books online

- legal aid

- case management

- victim \& witness

- calendars

- reports

- administrator

- docket enterprise

- information assembles

- legal bar

- meta reveal

- billing

- price master

- financial

- account for client and office

- office advance

- billing \& control

- time slip

Spider Law

Malaysia,

Malaysia

- follow up and workflow case

per license

- document assembly

- fix deposit

- payroll

- bill generation wizard

- RFID

- account maintenance

- group account

- database backup

- client's case file

- file category

- foreign currency

Ecolaw

Malaysia

- import data from UBS/ client account

$£ 1,100$

per license

- legal practice detail

- project transaction

- administration of user access
USD495

per license

USD600

per license / user

RM188 per year

$\mathrm{RM}$

1230.00 per license 


\section{A. Proposed Application: CAIS@Law}

Based on literature review, the features of law firms in Malaysia are differ from those overseas in terms of firm procedures, business processes and focuses. The proposed application namely CAIS@Law, focus on three basic modules identified based on the mostly required needs of SMEs legal firms. The modules are client's profiling, client's accounts and office's accounts. The client's and office's accounts should be managed separately to improve the accountabilities of account management. While, the client's management module is specifically designed to keep the track of client's accounts and transactions, hence for every documented transaction, users are able to view the details, thus monitoring the process in a more systematic and organized way. The developed system will assist to ensure the flows of client's moneys are in compliance with the audit requirements as well as improving the managements and supporting paperless documentations. Furthermore, it functions as a practical, user friendly and cost effective system, especially for small lower firms due to its flexibilities and remote IT resources.

All the modules proposed to be in Service Oriented Architecture (SOA) as the business functions and processes developed are independent components with significant of interfaces. These components can be accessed by many types of applications and services in any platforms or languages in a cloud system. The realization of web services uses the Internet that connects the service providers and the consumers for the similar account's management system. Fig. 1 shows the actors of web service which are the providers and consumers can be included in any type of within a cloud computing environment.

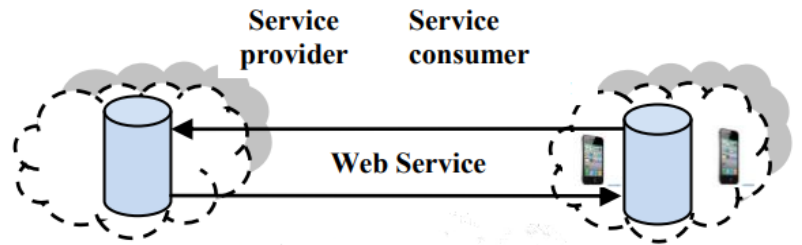

Fig. 1: The basic service oriented architecture of the $e$ business platform

Using this web service, users are able to create and administrate their accounts, available on the main server platform, which allows the features of proposed application:

i. Module of client profiling: The information from documents such as the receipts or bank checks considered as inputs and stored in databases. The data will be used as sources for other proposed modules. The module is used to classify the firm's clients with their profile according to their cases such as properties procurements or accidents. The administrative personnel can access information of the client's profile including related files of client and contacts, transaction details and related documents. This database is very crucial in sustaining the client's registration, file preparation, and authorization of the lawyer's appointment.

ii. Module of client account: This module used to register the client account transaction as practiced in clouds, so the client account web service can be integrated

cash book. The updates will be made when there is a cash flow in the client's account. As the output for this module, the summary of bank list and account, clients' account and transaction in different aspect of reporting can be generated as they are the required documents for audit purposes.

iii. Module of office account: This module proposed to be developed for financial management and transaction of legal firm's operation. The module is enable the income and expenses record keeping based on the firm services. The output for this module is financial statements and balance sheet statements. These outputs are necessary statements for internal decisionmaking.

\section{MATERIAL AND METHOD}

\section{A. Methodology}

The methodology for the proposed web services system is based on process approach. Web Service Description Language (WSDL) and web service flow language (WSFL) are employed as the core of services infrastructure based on previous research [14]. First of all, business process is identified in analysis frameworks to comply the web services applications. Then the second step is the definition of the design principles which are service couplings and cohesions.

Rapid Application Development (RAD) methodology is adopted and adapted for CAIS@Law development. This methodology can incorporate the project and development management including techniques, users, and tools in achieving the system's objective in a certain period of time as well as delivering the vital values of law firms. RAD manages the problems of time's constraints to urge the faster development of the system. There are four main processes in RAD and it requires optimum time for tasks completion compared to other software development methodologies. There are repetitive processes in the prototype development. Prototype is an output-based approach to create a demonstrable result as early as possible in order to get preliminary feedbacks prior to refining process. The feedbacks are normally the results verification that comply business process sides and the actual system's users. Prototyping requires a free approach for developments and focuses on the relationships and changes of the managements.

Each of phases in RAD is shown in Fig. 2. The outputs of every phase are also being represented. The stages are repeated and re-verified until the requirements are fulfilled.

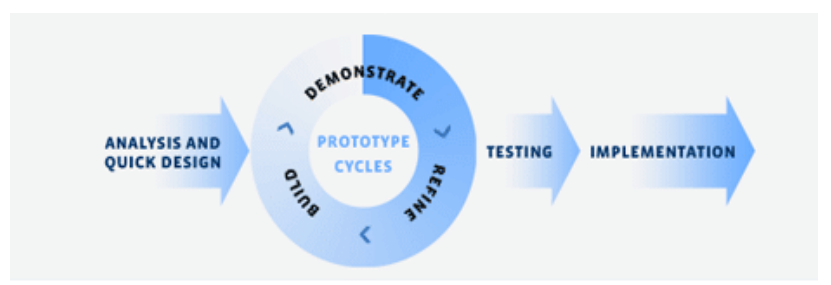

Fig. 2: Rapid application development

Blue Eyes Intelligence Engineering 


\section{WEB SERVICE ORIENTED ARCHITECTURE SOLUTION FOR ACCOUNTING INFORMATION SYSTEM FOR SMEs LEGAL FIRM}

The first phase of RAD is understanding and analysis. This phase entails the knowledgeable end-users to define the system functions and structured business process. This will include the discussion on selection of programming languages and database and the development tools. In this case, PHP scripts and MySQL database were selected to develop the prototype. PHP is a scripting tools to develop a dynamic web pages. PHP is open source software tool under the PHP License and can be used in a standalone application featured with interface and data designs. Overall structure of software is also defined in this phase in order to comprehend the system requirements before the prototype development.

The second phase is the repetitions of prototype's developments review from developing, demonstrating, and designing until the objective is achieved. The physical database design is created in this phase which focuses on design transformation into coding and connection between programming languages to database management system.

The third is prototype validation process in respect to business processes using set of tests. Programs for CAIS@Law are written as a series of separate modules and functionalities. The testing is carried out for CAIS@Law by functions cross checking system flow in integration set to ensure successful working interfaces between modules. These testing will generate and compile several analysis report. The report shows the corrected errors and highlights the features of prototype's enhancement. These processes are repeatedly performed until the prototype meets the business process. The last phase is the employment of the prototype in actual environment after several system and integration test.

\section{B. Proposed Architecture and Framework for CAIS@Law}

CAIS@Law is web service that is accessible via online web-based system. It can be run using any web browsers such as Mozilla Firefox, Chrome or Internet Explore at any operating system platform such as Windows, MacOs or UNIX. CAIS@Law is designed based on multi-tier clientserver architecture. Fig. 3 shows the three tiers structure of CAIS@Law architecture and frameworks. The computer of legal firm staff's is the client presented in tier 1 Presentation. Application processing and data management presented in tier 2 acts from a web server that provides data management services and employs the application logic to provide the required functionalities to end users. The web server generates CAIS@Law web pages, manages the financial transaction in client's and office's accounts and produces the reports for twelve logic functions as presented in tier 1. The main part of the system is the transaction part that incorporates the operation of office's and client's accountsx. The CAIS@Law database provides database services in Tier 3 Database processing. Efficient middleware that supports database queries in SQL (Structured Query Language) is used to handle information retrieval from the database.

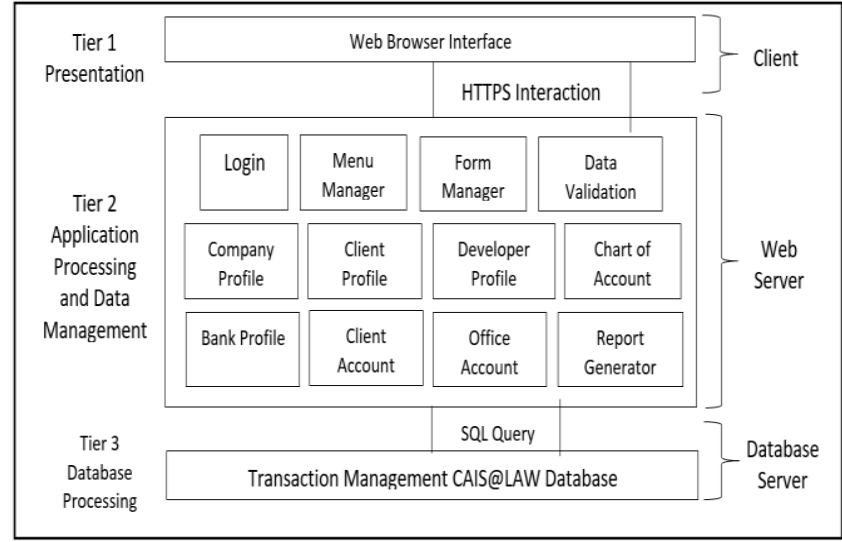

Fig. 3: CAIS@Law architecture and framework

\section{RESULTS AND IMPLEMENTATION}

\section{A. Implementation}

CAIS@Law system implementation will follow the preliminary action for realization of the developed system. In this implementation phase, the system is installed and employed for appropriate operation, including installation, configuration, running, testing and making any necessary changes. Fig. 4 and 5 show login interface and the homepage of CAIS@Law which sets up the menu of the system, respectively.

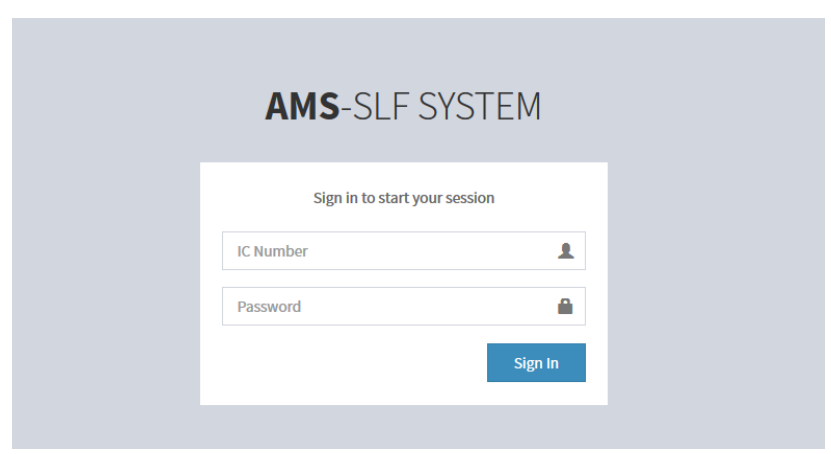

Fig. 4: CAIS@LAW login page

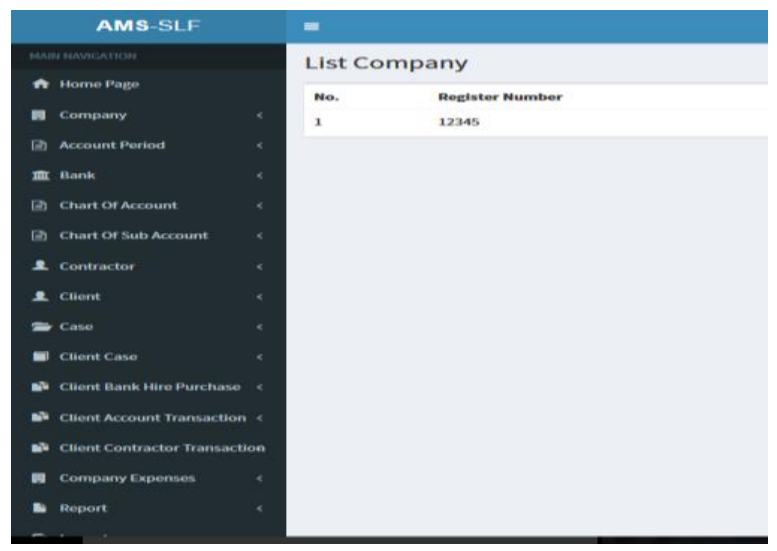

Fig. 5: Menu Manager

Fig. 6 shows the chart of the account system that start with code setting for company identifier by the user. 


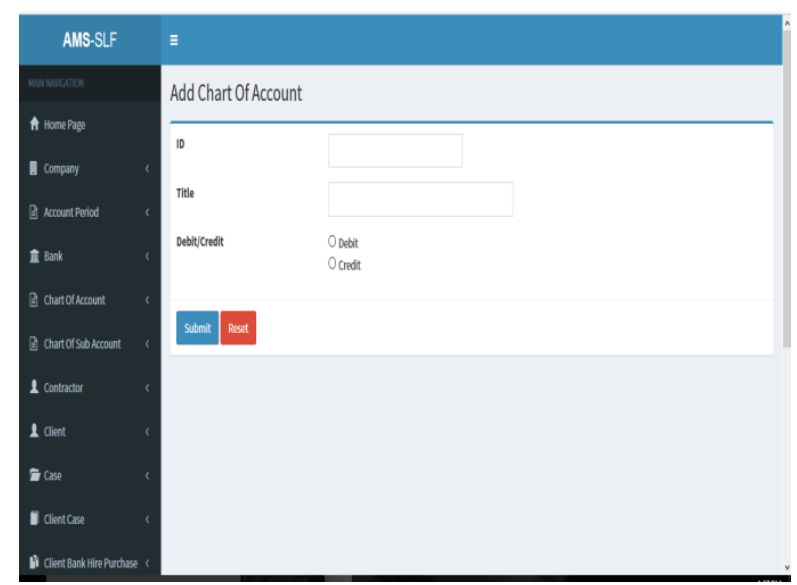

Fig. 6: Chart of account

Fig. 7 shows the transaction menu of cashbook for clients. This is the realization of the details of independent client's accounts for each case. The module consists of two functions. The first function is to add new account's transaction for a particular client based on their file's numbers. The second function is to display all related transactions for a particular client's file numbers.

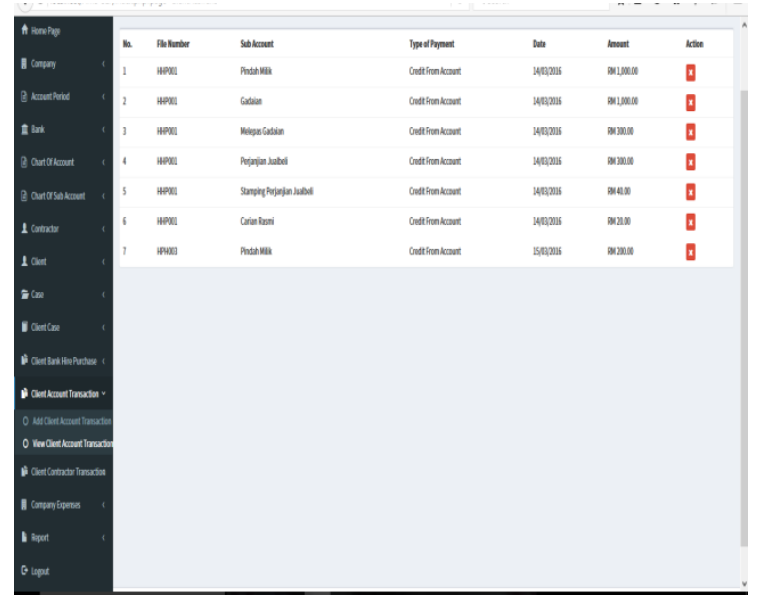

Fig. 7: Client account transaction

Fig. 8 shows the client ledger report which is based on respective client's case. This data is retrieved from the table of clients and client account.

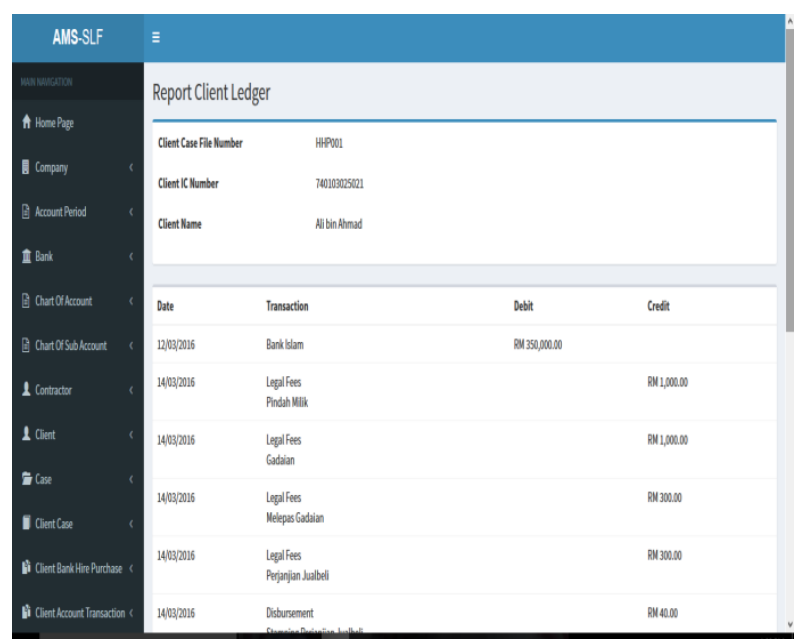

Fig. 8: Client ledger
Fig. 9 shows the report of profits and lost where all the records of the transactions are displayed based on company's accounting period. It shows the lists of company's incomes and expenses. The data is retrieved from office's and client's accounts tables. Some of the transactions in client's accounts will be a part of company's income.

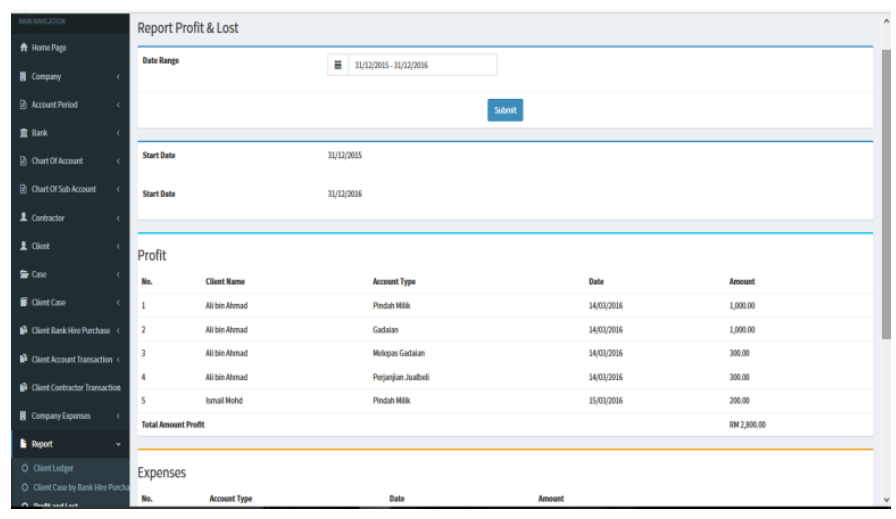

Fig. 9: Profit and lost

\section{B. Discussion and Analysis}

The system implementation has been analyzed based on real users' feedbacks from time to time. The results on evaluation of users' satisfaction as well as users' problems will be used to improve and refine the system. The CAIS@LAW system is proved to be applicable for law firms. Additionally, the flexibilities and portabilities of the proposed system in any machines or platforms are among its best advantages. The generated reports of CAIS@LAW are also adequate and sufficient to be submitted to the Bar Council as an evidence of a proper firm account management of the firms.

In the future, a more complex performance's evaluations as well as statistical analysis will be performed, taking into account the users' satisfactions, effectiveness, portabilities and flexibilities. The infrastructure could be improved using enhanced parameters and upgraded server to enable the online traffics and increase the level of system's responsiveness.

\section{CONCLUSION}

The proposed CAIS@LAW system that represents the business process for SMEs law firms in Malaysia provides a cost effective business accounts management. The paperless-encouraged system maintenance enhances the client information records for an easy access, tracking and reporting. CAIS@LAW is also able to track transaction records such as payments, debits and credits and also the unpaid billing. As regards to system requirements, CAIS@LAW business process is able to influence on existing hardware and network resources of the firm to safeguard existing IT investment. The main drawback of this system is that it needs to be upgraded if the firm's process of works changes from the existing process, for example if the firm receives concession agreement works which never been

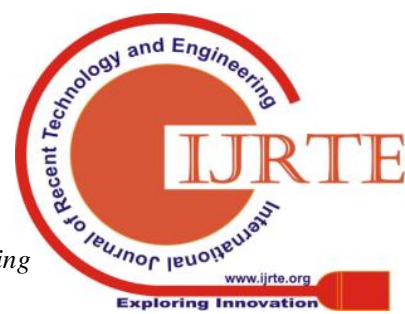




\section{WEB SERVICE ORIENTED ARCHITECTURE SOLUTION FOR ACCOUNTING INFORMATION SYSTEM FOR SMEs LEGAL FIRM}

done before, the firm need to request for an upgrade and some cost might be incurred. To summarize, CAIS@LAW is obviously suitable for small and medium size law firms for account management in order complying with the standard accounting method. Such software is easy to use and would be appropriate for lawyers who have limited knowledge in accounting.

\section{ACKNOWLEDGMENT}

This work was supported by University Grant (UniSZA/2017/DPU/78) Universiti Sultan Zainal Abidin, Terengganu and UniSZA Research Management, Innovation and Commercialization Center, Terengganu, Malaysia.

\section{REFERENCES}

1. A. Trigo, F. Belfo, and R. P. Estébanez, "Accounting information systems: Evolving towards a business process oriented accounting," Procedia Computer Science, 100, 2016, pp. 987-994.

2. R. Seethamraju, "Adoption of software as a service (SAAS) enterprise resource planning (ERP) systems in small and medium sized enterprises (SMEs)," Information Systems Frontiers, 17(3), 2015, pp. 475-492.

3. W. N. W. Ismail, M. Z. Mokhtar, A. Ali, and M. S. A. Rahman, "Do IT helps SMEs gain better performance: A conceptual analysis on RBV theory," International Journal of Management and Sustainability, 3(5): 2014, pp. 307-320.

4. R. Kouser, G. Rana, and F. A. Shahzad, "Determinants of AIS effectiveness: Assessment thereof in Pakistan," International Journal of Contemporary Business Studies, 2(12), 2011, pp. 621.

5. J. Zhang, H. Li, and J. L. Ziegelmayer, "Resource or capability? A dissection of SMEs"e IT infrastructure flexibility and its relationship with IT responsiveness," Journal of Computer Information Systems, 50(1), 2009, pp. 46-53.

6. N. F. M., Fadhil, and N. F. M., Fadhil, "Managing company"s financial among small and medium non-manufacturing companies," Far East Journal of Psychology and Business, 2(1), 2010, pp. 17-36.

7. S. Sian, and C. Roberts, "UK small owner-managed businesses: Accounting and financial reporting needs," Journal of Small Business and Enterprise Development, 16(2), 2009, pp. 289-305.

8. T. H. Nguyen, "Information technology adoption in SMEs: An integrated framework," International Journal of Entrepreneurial Behaviour and Research, 15(2), 2009, pp. 162-186.

9. B. Gullkvist, Towards paperless accounting and auditing. Finland: E-Business Research Center, 2002.

10. F. T. C. Tan, "A perception-based model for technological innovation in small and medium enterprises," 18th European Conference on Information Systems, 2010, pp. 1-13.

11. A. Shabanesfahani, and M.A.F. Tabrizi, "Information technology adoption and related policy issues in Malaysia," Journal of Environmental Science, Toxicology and Food Technology, 2(1), 2012, pp. 43-47.

12. Z. A. A. Ghadas, W. N. W. Ismail, A. A. Aziz, N. A. Harun, M. Jusop, and C. A. A. Rahman, "LAFAMS: Account management system kit for Malaysian small legal firms," Pertanika Journal of Social Sciences and Humanities, 23(S), 2015, pp. 241-252.

13. M. B. Romney, and P. J. Steinbart. Accounting, Information Systems. Arizona: Pearson, 2012.

14. Y. Baghdadi, "A methodology for web services-based SOA realisation," International Journal of Business Information Systems, 10(3), 2012, pp. 264-297. 